\title{
Virtual Reality and Immersive Simulation Technology Outside Video Gaming: Enterprise Applications and Potential Implications
}

\author{
Marco Remondino \\ Department of Economics \\ University of Genova \\ Email: marco.remondino@economia.unige.it
}

\begin{abstract}
The present paper explores the implication and uses of immersive simulation technologies, such as virtual, augmented and mixed reality, in management, business and organization fields. After a long gestation period, during which such technologies have been at the development/prototypal stage, in recent years we are finally witnessing the arrival of consumer based solutions, mostly driven by the videogaming industries. The crowdfunding success of Oculus Rift, which has probably been the first strong indicator that mainstream market was ready for virtual reality or, more recently, the exploit on Kickstarted of the Chinese company Primax, with $\$ 4.2$ million raised, are proving that more and more interest is being devoted to these technologies. As often happens, even if the most obvious use of certain technologies is in the consumer and mainstream field, those can also be applied in the enterprises. The immersive technologies are no exception and several applications have already been developed to leverage the use of virtual, augmented or mixed reality in strategical marketing, corporate training, engineering and many more.
\end{abstract}

Keywords - Virtual Reality, Immersive Simulation, Video Gaming, Enterprise Applications, Potential Implications

\section{INTRODUCTION TO IMMERSIVE TECHNOLOGIES}

From the Treccani encyclopedia, Virtual Reality (VR) is defined in the following way: "VR is a "computer simulation of a real situation with which the human subject can interact, sometimes through unconventional, extremely sophisticated interfaces, such as glasses and helmets on which the scene is represented and sounds are reproduced, and gloves (datagloves) equipped with sensors to simulate tactile stimuli and to translate movements into instructions for the software".

Born as a literary invention, a sort of VR is already present in the $1930 \mathrm{~s}$ in the short story of Stanley G. Weinbaum "Pygmalion's Spectacles". In the story, the main character Dan Buker meets Albert Ludwig, a professor who invented a pair of glasses that allowed him to enter a story that involved sight, taste, smell and touch, and allowed him to interact with the characters.

In 1966 virtual reality was used by US military aviation in the form of flight simulators. In 1968, computer scientists Ivan Sutherland and his student Bob Sproull created "The sword of Damocles", developing and building the first wearable VR viewer. The technology was primitive and designed to help helicopter pilots to practice night landing. However, the viewer was so heavy that it had to be supported by suspended supports, hence the choice of the name for the project.

The development of augmented reality devices continues between the 70 s and the 80 s, but only during the 90s some significant progress was achieved. In 1993, Sega designed and produced the Sega VR, a lightweight virtual reality viewer designed to be used with the Mega Drive, a gaming console. The viewer, which never reached the market, was equipped with a LCD screen and stereo headphones. Inside there were sensors that tracked the movements of the user's head. Also Nintendo tried to enter the virtual reality market, first with the Power Glove in 1989, and then with the Virtual Boy in 1993. Both products were performing poorly and, market wise, they were a flop. The Virtual Boy also created feelings of headache and nausea to users as the screen showed everything in black or red at very low resolution and frame rates.

Finally, we come to the present day when the devices for virtual and augmented reality are multiple, but we can distinguish them in two categories:

- VR headset for PC and console: this category includes augmented reality viewers that are connected to a PC or console for use. In this category the most popular are: Oculus Rift, HTC Vive, Sony PlayStation VR.

- Mobile VR headset: this category includes viewers that need a smartphone inside to work or are completely standalone. In this typology the most popular are: Samsung Gear VR, Google Daydream View, Google Cardboard or, more recently, the Mirage Solo (jointly developed by Google and Lenovo).

Virtual reality (VR) is only one out of the three "immersive technologies"; we can in fact mention, with a different user involvement and often different uses, augmented reality (AR) and mixed reality (MR). In order to delve into nomenclature:

- Virtual reality: with this technology the user is immersed in a completely virtual environment within which he can move and interact with it. The hardware 
required for virtual reality is equipped with sensors that trace the user's movements and then replicate them within the virtual environment.

- Augmented Reality: with augmented reality the user has a new perception of reality in which real physical environments are amplified by superimposed images and information generated by the computer. Unlike the virtual reality in which the user is immersed in a completely virtual environment, augmented reality uses the existing real environment and superimposes virtual information on it, hence "augmenting" it. With this technology virtual and real context coexist.

- Mixed reality: with mixed reality, the user is able to navigate both in the virtual environment and in the real world. Virtual objects are placed in the space of the real world. By moving towards virtual objects they become bigger and vice versa; while moving around virtual objects we can see them from different perspectives.

Virtual objects, therefore, replicate the behaviour of real objects. Moreover, with mixed reality the user has the possibility to interact and manipulate virtual objects. Here too, as with augmented reality, virtual and real context coexist.

TABLE 1. TECHNICAL COMPARISON AMONG IMMERSIVE

\begin{tabular}{|c|c|c|c|}
\cline { 2 - 4 } \multicolumn{1}{c|}{} & VR & AR & MR \\
\hline $\begin{array}{c}\text { Rendering } \\
\text { complexity }\end{array}$ & Very high & Low & Variable \\
\hline $\begin{array}{c}\text { Display } \\
\text { quality }\end{array}$ & $\begin{array}{c}\text { Highest res } \\
\text { Fully } \\
\text { immersive } \\
\text { Wide FoV }\end{array}$ & $\begin{array}{c}\text { High res } \\
\text { non-immersive } \\
\text { Real vision } \\
\text { FoV }\end{array}$ & $\begin{array}{c}\text { Highest res } \\
\text { Variably } \\
\text { immersive } \\
\text { Variable FoV }\end{array}$ \\
\hline $\begin{array}{c}\text { Sensors } \\
\text { accuracy }\end{array}$ & Medium & Very high & Very high \\
\hline
\end{tabular}

In table 1 and 2, a comparison among the three mentioned technologies is proposed first for the technical (hardware) features, then for the specific uses.

It is important to notice that the most advanced technology seems to be MR, even if it's not yet developed at its full potential (as of 2016). In the future it could possibly replace both VR and AR, by integrating both of them in one single, unified device.

TABLE 2. SPECIFIC FEATURES OF IMMERSIVE TECHNOLOGIES

\begin{tabular}{|l|c|c|c|}
\cline { 2 - 4 } \multicolumn{1}{l|}{} & VR & AR & MR \\
\hline Augments the real world & & $\mathrm{X}$ & $\mathrm{X}$ \\
\hline $\begin{array}{l}\text { Blends holograms with real } \\
\text { world }\end{array}$ & & & $\mathrm{X}$ \\
\hline $\begin{array}{l}\text { Totally simulates a virtual } \\
\text { world }\end{array}$ & $\mathrm{X}$ & & $(\mathrm{X})$ \\
\hline
\end{tabular}

\section{ESTABLISHED USES FOR IMMERSIVE TECHNOLOGIES}

To date, the videogame industry is the sector that better exploits and further develops the technology of VR. As far as Roger's model is concerned (figure 1) VR is now (as of 2016) at the "innovators" stage. It is possible to forecast a modest increase for 2017 and 2018, while a more important growth can be imagined for 2019 and later years, when VR will reach the majority of potentially interested customers. In particular, it is estimated that, by 2025 , VR within the gaming market will be worth 45.09 billion dollars. In fact, it is expected that native VR consoles along with VR addon devices for PCs will be preferred by consumers for gaming, compared to desktops and smartphones that offer a less immersive experience.

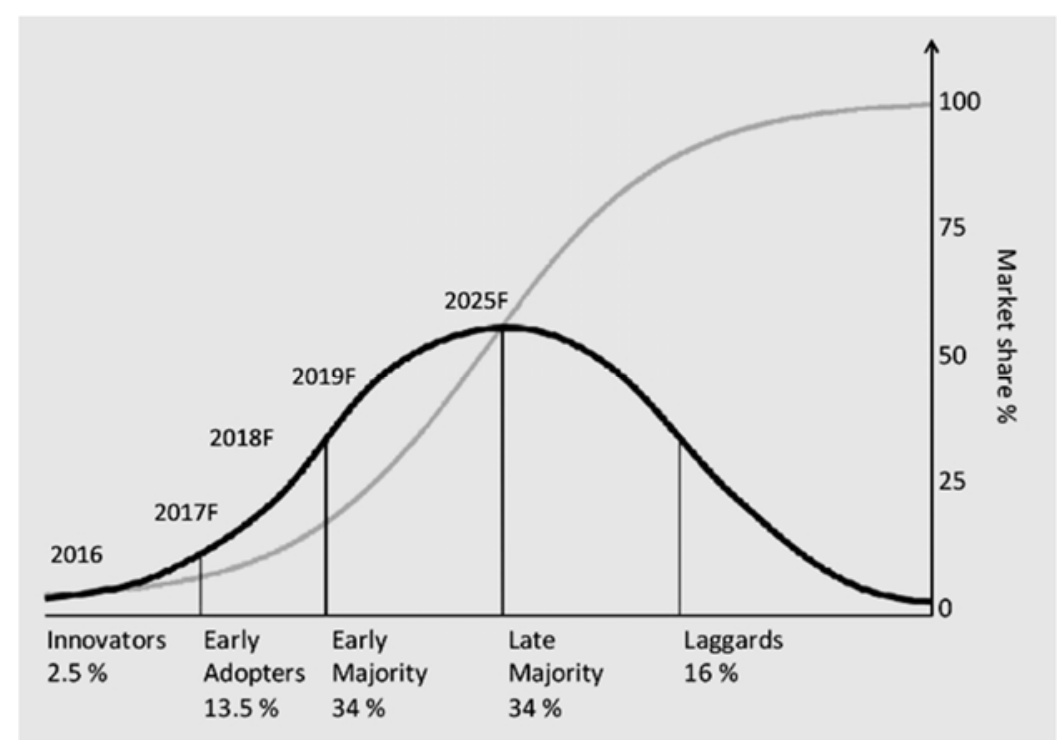

Figure 1. Projection of VR diffusion on the market, using Roger's innovation curve 
Not only the gaming industry uses immersive technologies; for example, aviation, medicine and the army employ virtual reality to train pilots, doctors and soldiers. In this way the virtual environment replaces expensive tools, dangerous situations or delicate technological tools. In the following, a brief excursus is carried on, to analyse the most frequent fields in which VR and AR are used.

\section{A. Aviation}

In the aviation sector, airline pilots use realistic cockpits in virtual flights. For this purpose, Boeing has developed the Constant Resolution Visual System, or CRVS, a highdefinition simulator for immersive training with a $360^{\circ}$ field of view that allows the pilot in training to have a very detailed simulation that translates into a flight experience as close to reality as possible.

Easyjet, the well-known UK-based low cost airline, has introduced the use of virtual reality for two purposes:

1) Training the crew, through virtual models of aircraft cabins. In this way, the crew is trained to respond to difficult situations that may arise during flight, be they emergency situations or unmanageable passengers.

2) Diagnosis of technical problems in real time and remotely. Through the use of virtual reality and augmented reality, an engineer can help a pilot or another engineer with a technical problem. This method is mainly used for requests for technical assistance from airports in locations off-centre, with respect to the Easyjet network; in this way you act more quickly and avoid e-mail and telephone communications with the Operation Control Centre, which may not lead to the solution of the problem because those who should solve the problem do not have a true and correct picture of the situation, but only a verbal description of it.

Military pilots also use VR for training purposes. Realism is critical for effective training. Accurate materials and life-like training environments mean soldiers can learn faster, better and less expensively. VR immerses soldiers in a variety of highly realistic combat scenarios. One VR station can train a soldier for multiple scenarios such as driving a tank, reacting under gun fire or reloading a rocket launcher. Conducting this type of multipurpose training from a soldier's home base or while on deployment makes VR a highly efficient and cost-effective training tool for military organizations.

There are therefore different uses that can be made of virtual reality in the aviation sector. As we will see later, as a side use in this field, virtual reality is also used to provide entertainment on board aircraft or to treat the phobia of flight.

\section{B. Cinema and Entertainment}

As far as entertainment is concerned, several start-ups are moving on to create headsets, i.e. helmets for virtual reality, and provide entertainment to the consumer. Among these, the Franco-American start-up SkyLights has produced $3 \mathrm{D}$ helmets for virtual reality, able to isolate airplane travellers within a cinematic world. The first company to offer these headsets to its passengers is XL Airways France, the French low cost airline, which for $€ 15$ allows travellers to immerse themselves in an individual cinema and enjoy the latest films released. Air France also tested the same service for business class passengers on the Paris-St. Martin route. Passengers could choose between 40 titles, in $2 \mathrm{D}$ and $3 \mathrm{D}$, and watch the film through simulation of a screen similar to the huge IMAX standard. Benefiting from noise cancellation, the passenger is completely isolated from external distractions.

Not only airlines, but even cinemas are experimenting with virtual reality to offer the viewer a completely immersive experience. In 2016 in Amsterdam, the first VR cinema opened, where customers sit in rooms without screens on swivel chairs equipped with high definition VR viewers and audio headphones. The films are specifically designed for $\mathrm{VR}$, in fact the viewer can rotate $360^{\circ}$ and freely look around in the virtual environment.

Virtual reality also enters theme parks such as Disneyland, which allows its visitors to experience a simulated experience within the Star Wars world. With virtual reality you can explore the space or planets that appear within Star Wars movies. Other parks, on the other hand, have combined the real experience of roller coasters and drop towers with virtual reality, creating the VR rollercoasters. This kind of attractions combine fantastic virtual environments with real forces and sensations, such as speed, air friction and gravity.

As has often happened, the entertainment industry is at the forefront of implementing a new technology that brings new customers. A few years ago 3D technology was employed, while today it's the turn of VR.

\section{Medicine}

There are many ways in which augmented reality and virtual reality are, nowadays used in the medical field.

The first and most relevant is, for sure, the use of virtual reality to train new surgeons. If, previously, practice corpses and assist experienced surgeons during operations were the only way for practical learning, now virtual reality allows surgeons to practice without risk, even in infrequent situations. It is therefore possible to work in the virtual environment, using virtual tools, and then transfer the new skills acquired in real situations in the operating theatre.

VR and AR are also used to treat phobias, such as fear of flying. Estimates declare that among 10 and $20 \%$ of 
people are afraid to fly, hence therapists use VR to project patients into a virtual flight experience and monitor their behaviour. In this way, therapists are able to understand which part of the flight experience causes most anxiety and thus find a way to treat this fear in the best way possible. Not only phobias can be treated, but also cases of posttraumatic stress. Patients, who in this case are veterans who continuously relive the traumatic events of war, are virtually projected within those events, but in a real controlled environment, to learn how to manage these stressful events that lead to self-destruction of the patient.

\section{Manufacturing}

Ford Motor Company, a well-known US car manufacturer, has been using virtual reality to develop car design since the $2000 \mathrm{~s}$, but it is in recent years that virtual reality has taken on a more central role during development.

With the help of modern Oculus Rift and HTC Vive headsets, Ford employees can walk around the car under development and look at it from different points of view. Not only that, you can also sit inside the vehicle, facilitating the decision making process of engineers and designers to achieve the final result. As the use of virtual reality increases, society builds fewer and fewer physical models and more virtual models. Ford has succeeded in reducing the design time of new models, allowing engineers and designers to experiment with different configurations more easily during the development phase; the virtual reality has also allowed more teams in different parts of the world to collaborate on the same virtual project without having to travel.

Ford is not using VR and AR only to help design new vehicles but also for the development of cars with autonomous driving technology (driverless cars). At the "Ford Research and Innovation Centre" in Palo Alto, virtual test drives are run to study how autonomous vehicles interact with pedestrians, replicating real traffic conditions to better develop the autonomous vehicle responses.

\section{IMPACT OF IMMERSIVE TECHNOLOGIES ON SOCIETY AND ECONOMICS}

The rapid growth of the mobile sector has had incredible returns, and thanks to cost reductions and improvements in the quality of motion sensors, displays and processors, it has enabled the development and emergence of "modern" immersive technology. Systems that were previously exclusively available to large companies or the navy are already spreading, at lower prices, to the rest of businesses and above all mainstream consumers.

As an effect of this and assuming that these technologies will continue growing as forecasted, as a first step it will be possible to observe the creation of new markets: this technology is in fact usable in many different situations, ranging from the relative straightforward videogame market to the already mentioned field of medicine, but will also be used more and more in other sectors, e.g. architecture, sport industry and so on.

It will create a strong demand for both software (increasingly realistic and fluid graphical engines and real time environments) and hardware (high resolution headsets, more and more precise sensors and so on) and therefore for increasingly more pervasive media. In addition to these elements it is easy to imagine that an increasingly complex and better software for VR and AR will allow a complete customization of the virtual environment in which people will dive. These elements will create a strong demand that will have to be satisfied by a fast and effective supply. These new consumer needs will be met by companies that are already deeply investing in these technologies, such as, for example, Facebook and Google, or start-ups that will be able, with innovative ideas, to reduce the operating costs, and thus to assert themselves in these markets.

Obviously, there will also be repercussions on existing markets: virtual reality presents itself as a tool able to completely change the interactions between companies and people, so it will have a strong impact in the management methods of advertising and sampling products: being able to "see" and "test" the product as if it were in front of us, being able to touch, analyse and therefore understand, in a very short time, the possibilities and problems related to its use, will revolutionize the way companies approach customers. Enterprises will need to focus more and more on the customization of the product on the basis of consumer expectations and demands, a phenomenon that is already fundamental in the strategies of today's businesses, but that will become increasingly important.

The affirmation of virtual reality will obviously also lead to the obsolescence of some technologies that are dominant today: current social networks will either change to adapt to change and to this new reality, or they will be considered outdated and their demand will decrease, while new ones with full support for immersive technology will arise. An example could be Skype, that will probably need to be reimagined as a real virtual meeting system, in place of a "simple" video calling application.

Finally, virtual reality can also have positive effects within companies themselves. The application of internet and broadband has already made it possible to send large amounts of data over huge distances, hence reducing costs. With virtual reality it will be possible to make the most of companies' resources, especially in the design and intercompany communication phases. In particular, in the first phase, it will be possible to actively interact with physically distant subjects on a given project: this will reduce time and at the same time increase efficiency; for some companies, it will also be possible to allow some workers to work from 
home, thus eliminating the need for offices, thereby further reducing costs.

It is important to note that virtual reality is much closer to being spread among businesses than among final consumers. This is partly motivated by the fact that businesses can justify higher costs for the implementation of this technology, while consumers cannot: for businesses there is a return, it would be an investment, for consumers it would be nothing more than yet another form of entertainment. In addition, a perfect and complete virtual immersion experience still has to wait a few years to see the light, but not all companies need such a high level augmented reality: the levels reached in 2016 and 2017 already give some companies the opportunity to improve the tools they currently use, and to transform their ideas into something more tangible. For these reasons, the future use of this new technology will be more entrepreneurial than just videogame entertainment.

Therefore, there are many companies today that are raising funds for this technology and launching their projects on the market as soon as possible. However, only because technology exists does not mean that it must be adopted immediately. For many traditional companies, the time has not yet come to invest in virtual reality. They should analyse in depth the techniques, platforms and tools of this new technology in order to better understand how it can be adapted to their own business strategies and how it can create the greatest benefits for them. Companies must start thinking about how to use this technology, and they must do so now, or risk losing the ideal moment to enter the market, fading their potential competitive advantage. To avoid this, they need to work with experts to create new methods, to combine their strategies and this technology, either by incorporating it into the company's strategies, or by creating real new strategies based on it. The smarter market leaders know that they already have leading position and explore how virtual reality will influence their business, trying to increase their competitiveness. What they have to do is understand which will be the best ways to act, in order to support their experience in virtual reality and to do so the first steps are to invest in both hardware and software, make improvements to existing computers and technologies and expand their own data collection centre. But also they need to invest in organizational change and managerial strategies, to adapt and leverage more and more on the new technologies.

\section{CURRENT AND FUTURE USES OF IMMERSIVE TECHNOLOGIES WITHIN ENTERPRISES}

Both VR and AR therefore introduce new opportunities to transform or improve companies, particularly in the areas of communication and collaboration, learning and simulation, marketing and sales; but immersive technology can also be means to reinvent the experiences of both workers and customers.
In the following table 3, VR uses are divided according to the precision with which the software and hardware can/should reproduce reality, and the different uses that can be associated with it according to the distinction on destination: whether VR is used within the company, or in communication/sales with customers.

TABLE 3. USES OF VR IN DIFFERENT SECTORS AND PRECISION NEEDED FOR THE DEVICES

\begin{tabular}{|c|c|c|c|}
\cline { 2 - 4 } \multicolumn{1}{c|}{} & Low precision & $\begin{array}{c}\text { Medium } \\
\text { precision }\end{array}$ & High precision \\
\hline $\begin{array}{c}\text { Internal } \\
\text { use }\end{array}$ & $\begin{array}{c}\text { 1) use of VR in } \\
\text { more marginal } \\
\text { fields (e.g. } \\
\text { Sport) }\end{array}$ & $\begin{array}{c}\text { 2) Learning } \\
\text { and training } \\
\text { of workers }\end{array}$ & $\begin{array}{c}\text { 3) More specific } \\
\text { tasks: medical } \\
\text { field, prototype } \\
\text { design }\end{array}$ \\
\hline External & $\begin{array}{c}\text { 4) Marketing } \\
\text { campaigns for } \\
\text { services }\end{array}$ & $\begin{array}{c}\text { 5) Marketing } \\
\text { campaigns } \\
\text { for products }\end{array}$ & $\begin{array}{c}\text { 6) Sale of } \\
\text { devices to } \\
\text { consumers } \\
\text { (Video game } \\
\text { department, } \\
\text { entertainment) }\end{array}$ \\
\hline
\end{tabular}

Six categories have been identified:

1) For the first one, high precision is not necessary because, within the sport field, VR is generally used for the study of strategies, and preparation for subsequent matches, so even if the real world is represented with less precision, this does not affect the achievement of the objectives.

2) In the second one, a higher degree of precision is necessary, since workers must be aware of the machines they will then work with in reality.

3) Finally, in the design phase or in the medical field, the precise representation of reality becomes a fundamental element to avoid errors that could have serious consequences.

4) For services, marketing campaigns are very much based on the messages they want to send, so even if the accuracy of the devices is not too high, it is possible for companies to achieve their goals while keeping costs down.

5) For product marketing, greater precision is needed to avoid too many discrepancies between what VR represents for the product and what the consumer actually buys.

6) Finally, for entertainment (Cinema in VR, or videogame market), greater precision is necessary for a greater immersion of the consumer, and, consequently, greater satisfaction of the products purchased.

In the following, some different possibilities for the enterprises are listed, offered by the immersive technologies in the fields of corporate training and elearning, teleworking and distance working, meetings and team working, marketing and sales, manufacturing, real estate. From a recent research, the distribution of VR patents outside the gaming industry is reported in figure 2 . 


\section{VR patents per sector (excluding video gaming)}

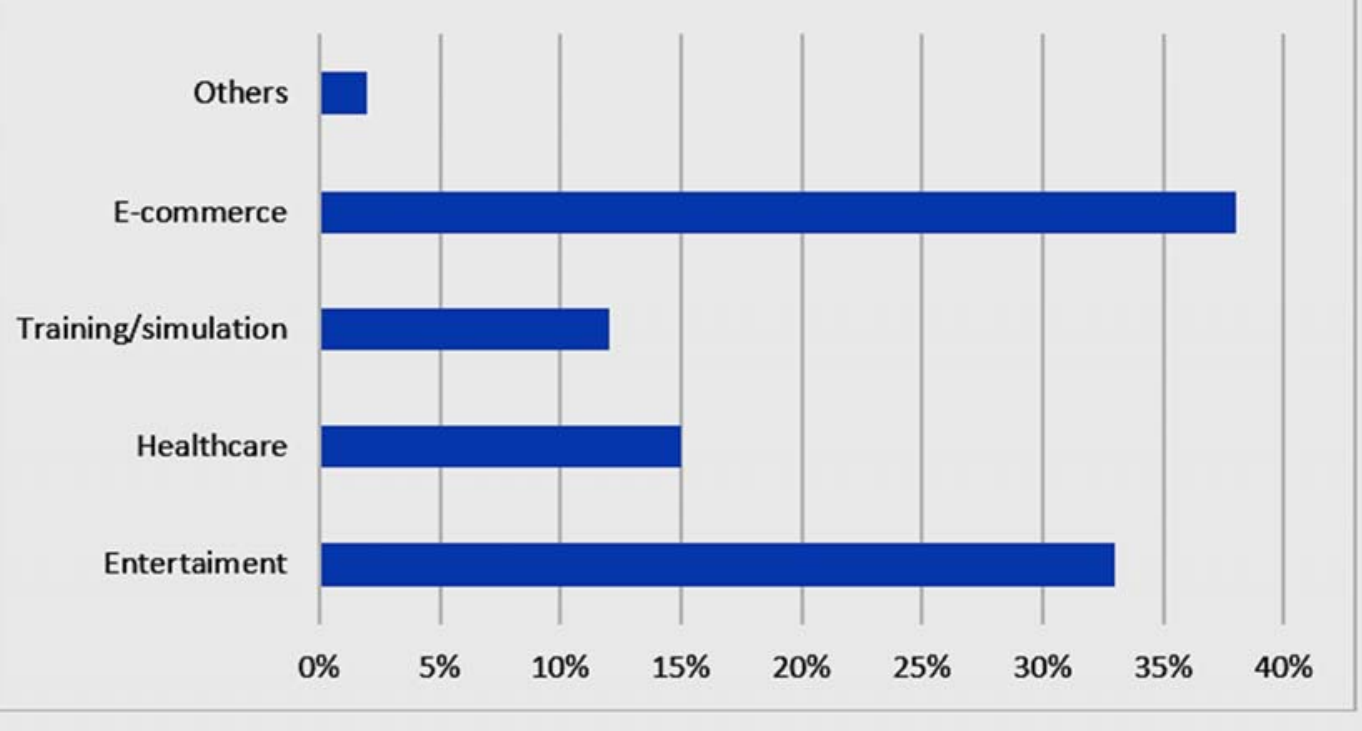

Figure 2. Percentage distribution of VR patents per sectors outside the gaming industry

\section{A. Corporate Training and e-Learning}

This is, perhaps one of the most important uses for this new technology. Whether it is training a soldier on a virtual field or training a sales manager, virtual reality gives the chance to enter the world of learning more efficiently and without leaving home or the office. This allows each company to train all its employees more quickly and frequently, thereby increasing the competitiveness of the company itself. Financial managers would then be able to train in a virtual environment, improving their communication and leadership skills. This is what Jeff Kagan, one of the most famous and quoted American analysts, tells us.

The combination of virtual reality with particular types of sensors, such as Leap Motion (technology capable of recognizing hands and movements with a precision of 0.01 $\mathrm{mm}$, and reproducing them on the computer), will create the possibility for the company to train its employees in simulating environments in which they use extremely sophisticated and expensive tools, allowing them to learn how to use that particular device without actually using it, thus reducing the possibility of incorrect use. It would also make it possible to recreate high-risk situations, without however meeting the consequences of the real world in case of error. In fact, there are several jobs in which the learning phase is very delicate and difficult (for example, the already mentioned surgeon's apprenticeship course, but also jobs related to nuclear power plants and so on) which require the difficult challenge of training in the most realistic way possible, but without actually moving from home or the office. Virtual reality would be able to fill the present gap between the real world and the training path through incredibly precise and realistic simulations. The experience in a virtual environment is, in fact, able to generate greater effects than any other type of media (e.g. video or even internet), so it is useful both to train workers in difficult duties, and also with regard to the development of more common skills, doing tasks in a faster and more effective way. It can be particularly useful for training workers who find it difficult to learn through traditional, one-to-many methods.

Another advantage comes when we think about the seminars that many workers have to follow in order to refine their skills and competences and keep them up with the constant technological development, not to mention the potential saving in direct expenses: there would no longer be any need for the company to rent hotel rooms or flights for all the employees to travel to the place where the seminar is held. Instead, it would be possibly enough to send a few people, while those who remain would still be able to participate virtually, through the immersion in a virtual environment, observing their colleagues physically present at the seminar, and learning from them.

When we think about training in virtual environments, military or medical environments immediately come in mind, either because of the difficulty of learning certain skills or because of the risks involved. Instead, an example of a company that already uses this technology without being connected to these two fields is that of the National Grid, a company that supplies gas and electricity in England and the North-East of the United States. National 
Grid's virtual workout allows students and workers to simulate decisions they may be required to take in the real life, such as which tool is needed for a given task or which security equipment is best for specific situations. Thanks to virtual reality, they have been able to move from simple and dull Power Point presentations to models that people can "touch" with their virtual hands. In addition, students and youths are often already familiar with this kind technology, since they grew up with video games, says Patrick Hallihan of National Grid. The company hired several experts from outside the company to implement and improve the virtual training system. They bought components from Premtech, which helped them import National Grid 3D models into the Unity graphics engine, which has been used to develop different virtual environments. Beyond the benefits of increased security, National Grid has been able to greatly reduce travel costs that were necessary to learn and improve certain skills: according to the company, the money saved was enough to support the cost of virtual reality hardware after a single workout session.

\section{B. Work Meetings, Distance Working and Job Interviews}

This is one of the fields where technological advancements in media have contributed the most, but they have never been able to totally replace the real meetings in the workplace. Today, thanks to both virtual and augmented reality, one could finally succeed where a static and flat communication has so far failed: in replacing the interpersonal relationships among workers, greatly reducing communication problems. Both of these technologies offer entrepreneurs the opportunity to change their business strategies and change the way workers interact with each other and with their superiors. Virtual reality should therefore be able to improve relationships among employees working from home with their managers or other co-workers. Just think of a person who works from home, in a virtual environment, surrounded by his colleagues in a virtual office (represented through real time rendered 3D, realistic avatars). This would allow the worker to feel part of a team, or to feel more involved in a meeting, which would obviously lead to a possible increase in sense of presence and, ultimately, productivity. It is also useful for the employer to see if a specific employee working from home is actually working, or if he is simply pretending or wasting time; these are some of the main advantages identified by Rob Enderle, US analyst.

A virtual meeting would therefore allow managers to meet their employees "face to face", and it would no longer be a matter of today's virtual meetings, where the various subjects are seated in front of monitors: the meeting would be held in a virtual environment where the various participants can communicate in a much more natural way. This translates in a reduction in business travel time and cost, provided that the company uses this technology efficiently and even a reduction in the administrative work involved in choosing accommodation and managing expenditure. Finally, there would also be a reduction in the time when workers are away from home and therefore not available for their families, with the elimination of downtimes due to office-home travels.

Another important use could be for job interviews: when virtual reality is accessible to most people, you can interview people in virtual environments. Large companies will be able to recreate virtual offices specifically for this purpose, like it happens today with teleconferencing. One of the reasons why face-to-face interviews are often preferred is that the way a person reacts to a question, and even body language during the interview is extremely important. Immersive technology would allow such information to be received in a way similar to reality, but at a reduced overall cost, hence an improvement of effectiveness and efficiency for recruiting and interviewing.

\section{Communication, Marketing and Sales}

Another obvious field in which virtual reality could potentially change the current behaviour is sales, and therefore advertising.

In table 4 , a forecast of sectors that will most likely benefit from VR advertising is shown.

TABLE 4. SECTORS THAT WILL MOST LIKELY BENEFIT FRO
MARKETING AND ADVERTISING IN VR AND AR
\begin{tabular}{|c|c|c|}
\cline { 2 - 3 } \multicolumn{1}{c|}{} & $\mathbf{V R}$ & $\mathbf{A R}$ \\
\hline $\mathbf{1}$ & Automotive & Automotive \\
\hline $\mathbf{2}$ & Gaming & Gaming \\
\hline $\mathbf{3}$ & Travel & $\begin{array}{c}\text { fast-moving } \\
\text { consumer goods }\end{array}$ \\
\hline $\mathbf{4}$ & Entertainment & Fashion \\
\hline $\mathbf{5}$ & $\begin{array}{c}\text { Property, Construction, } \\
\text { Real Estate }\end{array}$ & Entertainment \\
\hline
\end{tabular}

Companies will be able to attract potential buyers to purchase through virtual tests and trials, before the actual purchase happens. In order to succeed in this goal, with old technologies, it was necessary that the product was visualized from many angles and points of view, in order to give the consumer an idea, as realistic as possible, of how the product was. Immersive technologies go beyond this, allowing the consumer to keep the product in her virtual hands as if it were real, or even to test it in a virtual, simulated environment to understand all its potential, but also to perceive any potential defects. For these reasons, these technologies would be very well suited for both reasoned purchases and/or impulse and routine purchases. One example is buying a car: consumers will feel as if they were actually sitting in the car, in front of the cockpit, they will be able to feel what the driving and handling is and 
how the interiors are made, and they will also be able to see if and how spacious the car is. All this obviously before going on to make a real driving test and meet the seller in person. Hence, this could be preliminary to a real test, so that a potential buyer could discard the worst options without losing time in testing them for real.

In the field of Marketing, VR is already becoming a topic of a certain interest, in fact different subjects, including, among many others, Iris Worldwide, are taking an interest in this technology. More specifically, the application of virtual reality to create new advertising is interesting: this technology can be used to recreate a link with consumers that is more durable than alternatives, such as $360^{\circ}$ videos. The latter, at present, are certainly more easily available and viewable by more people, especially thanks to their distribution within social media, but have definitely a more modest impact on people. To mention a specific field in which this can be used, spots in virtual reality could have a high degree of involvement, that allows consumers to better remember a specific product and its characteristics. It should be remembered, however, that the costs of advertising these specific products or services through virtual reality are still high, especially since a specific purpose system is necessary for the devices that are made available to customers to try this experience in virtual space. This problem could be solved if virtual reality becomes an established technology among consumers, similar to what happened with smartphones, hence leveraging prices, but it is probably still too early for this

In any case, the potential in this sector has already been well understood by Alibaba, a Chinese company specialized in e-commerce, which has launched a new function, "Buy+", which allows users to select objects and accessories in virtual environments, despite the fact that the company knows very well that it can potentially take years before virtual reality becomes an established technology. In fact, Zguang Zhuoran, the director of Alibaba's mobile technology department, said that the VR and AR market has yet to develop and, even more importantly, businesses need more time to expand into this sector. In any case, this initiative helps consumers to see what the future of their purchases will look like with a 3D model, through a commercial headset. Alibaba is only one of the many enterprises in e-commerce that are embracing virtual reality and e-bay is interested in this technology.

If we talk about virtual reality applied to advertising the possibilities are endless; a specific example is Carnival, an American cruise group, which has started to use virtual reality to advertise its travels. The main target are potential customers who have never made a cruise and hence totally ignore the real experience. The objective is precisely to show newcomers what such a journey consists of, the experience is partly made up of advertising and partly of a virtual guided tour. Carnival has no real world data about the success (or lack thereof) of this initiative, but the impressions are positive on the customer's side, so that it is likely that the company will create new and more complex virtual experiences. However, some care must be taken: an advertising campaign in a virtual environment could be incredibly harmful precisely because of its immersion in a "non-real" environment: if this is not very well realized, it can leave the potential consumer with a feeling of uneasiness, which will have negative impacts on the promotion of the real product or service.

Moreover, an environment that recreates in a superficial way the real one does not allow a true and realistic test of the product itself. It is therefore essential for the use of virtual reality in these fields to be able to recreate the real world down to the smallest useful details. In any case, for VR advertising to become really pervasive and effective, it is again necessary to wait until virtual reality becomes established within a significant part of the population. Another example of a company that has recently decided to introduce this technology into its marketing strategy is Fiji Airways, that has given the opportunity to experience a trip to Fiji through the HTC headsets. The people who decided to try this experience had the opportunity to explore the different possibilities that a holiday in Fiji can offer. The airline's goal is obviously to try to increase the number of tourists, but it also aims to find out what the effect of this technology in marketing is: before and after diving in a virtual environment, a test of happiness and satisfaction has been proposed, so to assess whether this technology can be used to increase customer satisfaction and, ultimately, sale. Unfortunately, the data that they have been able to collect with this survey has not been published yet, but Franc Zvonar, head of the marketing department of Fiji Airlines, would like to implement this technology at a deeper level in the company's strategy, so it can be deduced that the results must have been quite positive.

\section{Other Uses within Enterprises}

There are many other potential uses for virtual reality in an enterprise, including information management and organization. There are several companies exploring new methods of data management through this technology, one example is VIEW, a tool used by NASA to recreate a virtual environment in which an operator can manipulate sensitive information and data. The objective is to develop a workstation that has a personalised interface based on the skills and competences of the operator, that can be easily reconfigured for various objectives. NASA is also developing a technology that allows live video to be inserted into a virtual environment, creating a fusion between a computer-generated background and video from a camera. This system would make it possible to lay the foundations for the creation of large computer databases. Virtual reality is also useful for data organization, many scholars are studying the visualization of databases in virtual environments, and also models to navigate in such spaces. As organizations and companies around the world 
enter data into databases, often only after making a paper copy, it would be very useful to develop new and more efficient methods of working with computers and databases. For now, some systems have been developed in a virtual environment to keep track of folders, subfolders and files on a computer. The aim is always to develop applications that use virtual reality, ensuring lower costs and increases in productivity of workers, it would not be enough to automate simple but boring processes.

Virtual reality can also be useful to reduce costs during the research and development (R\&D) phase: the construction of prototypes is always very expensive for the company, but through the creation of these in a virtual environment you could test the potential of new products without having to really create them, and therefore without wasting resources. Or it can be used to help you choose new offices when a company decides to expand or relocate its headquarters. Finally, last but not least may be the relationship among employees and their superiors: today there are two possible methods, either by e-mail or by comparison in person. Both present problems, however, the first is very cold and detached, while the second can lead to behaviour of mobbing, through virtual reality can eliminate both part of the coldness due to an indirect relationship, and the possibility of mobbing.

\section{NEW PROMISING APPLICATIONS FOR IMMERSIVE TECHNOLOGIES}

Besides those explored in the previous paragraphs, there are many more innovative and potentially revolutionary uses for VR and immersive technology. In the following, a brief overview is carried on.

\section{A. Pain Relief and Mental Health}

Two surprising medical uses, identified by Collette Johnson, Medical Director of Plextek Consulting, are in the fields of pain reduction and mental health. By 2020, virtual reality will be used by patients as a distraction technique. Excessive pain can be dampened by creating a virtual environment that allows the patient to be "distracted", immersing them in a calm and peaceful environment that is able to restore the patient to "normal", reducing the anxiety associated with the pain. Evasion from reality is a fundamental component of virtual reality and completely changes the way patients see both the world around them and their condition. This technology can offer a much more personalized approach to rehabilitation, tailored to the specific needs and wishes of each patient. However, before this type of therapy based on virtual reality takes off, it is necessary that it is developed according to precise specifications. Virtual reality is born with potentially damaging effects, as it happens for most technological innovations. There must therefore be a suitable system in place that can gradually bring patients in and out of the virtual world. The user must be psychologically prepared for what is going to happen and must not remain too long immersed, to prevent it from starting to lose conception and perception of what is real. A start-up is making its way in this area, the Applied VR, which, together with its partners, the Cedars-Sinai Medical Center, Children's Hospital Los Angeles and Stanford, has the aim of introducing an alternative to drugs for the treatment of pain. The basic idea is always to try to distract patients from pain, all based on a study by the Cedars-Sinai Medical Center seems to have shown that 20 minutes immersed in a calm virtual game can reduce pain. The effect of the reduction is very similar to that of narcotics, but it is potentially much cheaper. However, it must be said that this particular use is still in the testing phase, and cannot be used on all patients; if we combine this with the high costs of Applied VR devices, it is unlikely that we will soon see these instruments used in hospitals. However, the implications for clinical treatment are enormous, and if, as it seems, the trials are successful, this technology may change pain therapies in the future.

As far as patients' mental health is concerned, virtual reality can be used to better understand these problems. Parents who have children with schizophrenia, or other problems, such as paranoia or image disorders, can be immersed in a virtual world that simulates the effects of these diseases, so that they can understand how their children perceive the world around them. Often, in fact, the parents of children suffering from mental illnesses say that they seem to have "lost" their own child, that they have been forced into a world apart, unknown and incomprehensible. Virtual reality thus becomes a solution that can be both of help to the family and of help to the patient, understanding and keeping up with both physical and psychological conditions. The use of virtual reality is not only aimed at supporting families and patients, but also at healing them: South London and Maudsley NHS Foundation Trust, whose psychiatric institution is one of the most important in the world, has started to use this technology in phobias treatments. In a recent project, still in its early stages, using an Oculus Rift model of 2015, children suffering from obsessive-compulsive disorders were helped to overcome their repulsion for public toilets by immersing them in a virtual service environment while they were physically in a comfortable and safe place. Children could change several factors, such as the level of cleanliness of the bathrooms, while their temperature, heart rate and stress level were monitored by special tools. In addition, some progress has been made in the treatment of people who have suffered severe trauma. In this sense virtual reality has proved to be an extremely useful tool: modern medicine considers it essential for healing that a traumatized patient can face the situation that caused him trauma. This was usually done by trying to remind the patient of the trauma event, but often, due to a mechanism of self-defence, people could not mentally reproduce the 
situation, and therefore long rehabilitation paths were necessary.

Thanks to virtual reality, doctors are able to recreate the situations in which the patient was and make them live again in virtual space so that he can face them; they are also able to modify at any time what happens within that reality so as to "adjust" every detail according to the patient's indications. Through this experience it is possible to circumvent the mechanisms of self-defence of the human brain, thus succeeding in reproposing exactly the experience suffered by the patient.

In recent years, a project has also developed, the Walk Again Project founded by Miguel Nicolelis and other researchers at Duke University, whose aim is to help patients with paralysis in the lower limbs, trying to improve the conditions of these people, with the objective of the future, not yet achieved, to allow them to walk again. This project is based on two technologies: on the one hand an exoskeleton, designed to support these people, and on the other hand virtual reality. The latter is used by patients to familiarise themselves with and learn how to use the exoskeleton: through a helmet, signals can be sent to the exoskeleton, which should therefore move accordingly; the problem is that each person has a different neuronal activity, so it is complicated to create the software needed to read and send the signals of all the people who need it. Once the patient is familiar with the exoskeleton controls within a virtual environment, where he controls an avatar of himself, and the researchers have managed to recreate a mapping of the exoskeleton controls, we move on to the next step, where immersion in a virtual environment is no longer necessary, but specific slings are used. This project has obtained excellent results, it has in fact been possible to obtain some control over the leg muscles and in some cases the reclassification of paralysis from complete to partial; a specific and extraordinary case is that of a 32year-old paralyzed from the age of 19, who was able to move a few steps with the help of a sling and a therapist. These results are still far from full rehabilitation, but they still give much hope for recovery from this type of paralysis.

Moreover, the use of virtual reality in medicine is evolving in directions that are not really predictable: in England, we are experimenting with the use of virtual reality to train soldiers to assist their injured companions on the field. Soldiers used to train and develop their skills in this field on volunteers and empty offices; the system, created by Plextek Consulting, would allow the immersion in a virtual environment programmed as a war zone. The user would join a team of 8 subjects, and, following an explosion, would find an injured soldier. It is up to him to decide how to assist the injured person, what procedures to apply and to call a helicopter for evacuation. In addition, the system would allow you to insert complications during training, such as visibility limitations due to smoke/fog, gunshots or sudden changes in patient conditions, all to go and measure the reactions of the examined.

\section{B. Production of Goods}

As already stated, an emerging field of application for virtual reality is manufacturing. While at present there are already several uses for VR in this field, this is going to increase in the next few years. Production teams from around the world use this technology to optimize production processes, design and many other different operations. Virtual reality is basically a natural extension of CAD (computer-aided design), the computer system used until today to support the design activities of different products. Using this new technology, manufacturers can create $3 \mathrm{D}$ virtual prototypes to test the feasibility of new products before incurring the cost of creating physical models of these products. It also allows manufacturers to identify problems faster and designers to have a more accurate idea of what the end product will really be, thus incurring less costs than traditional physical prototypes, all this allows a reduction in the development cycle of new products.

A very interesting case is that of Ford. Ford has used different forms of virtual reality in its production processes since 2000, but in 2006 it redoubled its efforts in this regard, launching the Immersion Lab, a structure designed to allow designers and engineers to test various production or design possibilities using virtual reality, thus making Ford the first car manufacturer in terms of technological innovation in production processes. Inside the Immersion Lab engineers wear helmets for virtual reality and can walk around, inspect and even sit inside the prototypes of the cars they have just designed. In addition to the Oculus Rift device, the system consists of several other components including a huge screen in a $4 \mathrm{~K}$ definition, which allows other engineers, designers and executives to view the demo. Ford uses this system to examine cars both inside and outside, and any adjustment is automatically recorded inside the system. This structure is used throughout Ford's production line and has become a key element in the process of developing new products. For example, for the new Ford Mustang, engineers have modified the cut and coating of the dashboard and windscreen wipers to match the data from virtual environment diving so that they are hidden from the driver's view while not active.

In addition to the benefits of increased production speed and efficiency, virtual reality testing unlocks a whole range of possibilities that are unrealistic. Virtual reality allows you to perform quick $\mathrm{A} / \mathrm{B}$ tests on different vehicle configurations in a single session, which would require different models of the same car as well as a waste of time for reconfiguring the system in the real world. In addition, virtual reality provides greater consistency to tests, allowing engineers to isolate variables such as sunlight or temperature during tests. According to Elizabeth Baron, the 
director of the Immersion Lab, Ford had to overcome some problems regarding the use of this technology, first of all had to solve the problem of nausea and disorientation (a problem that was resolved thanks to the adoption of the most developed models of devices for diving in a virtual environment), then the fact that many executives did not want to use virtual reality in production processes, a problem that was partially solved given the benefits in terms of costs and efficiency that this technology brought to the company, and finally the time needed to create accurate virtual models, the creation of the first prototypes lasted about 2 weeks, while the time was optimized up to 4-8 hours per model. This virtual reality initiative has had a major impact on the cost, speed and efficiency of the production process. According to the vice president of the engineering department of Ford, using these virtual prototypes of has managed to advance by 6 months the time schedule for the design of new models, which have resulted in savings of millions of dollars. Since the establishment of this structure, Ford has steadily increased its commitment to the application of virtual reality, making it a fundamental part of the production process. In 2013 alone, Ford's designers created 193 virtual prototypes of cars. The success of this facility is so high that Ford is already planning to create a new virtual reality laboratory, as one facility no longer seems to be sufficient for Ford's engineers.

\section{Real Estate and Home Furnishing}

The real estate sector has never been famous for embracing new technologies, but with virtual reality this seems to be slowly starting to change. Virtual reality would allow the user to immerse himself in environments created specifically to be as realistic as possible, which would allow the creation of real virtual tours that would facilitate the sale of homes. This would create the opportunity for potential consumers to visit the different houses for sale, and analyse the interiors, the layout of the rooms and the area in which the house is located without having to move from their current home. Intermediaries and manufacturers are beginning to use this new method to increase sales; Wedbush Securities, an American analysis company, believes that the main reason behind Facebbok's purchase of Oculus VR is the potential that virtual reality has in this sector. Similarly, this system can be used in tourism, by hotels and farmhouses to attract new customers, one of the first countries to use virtual reality in this area was South Africa, combining this technology with binaural registration.

An example in this area is the experience of the IKEA. On 4 April 2016, they announced the release of an application: the IKEA VR Experience, which was distributed through Steam, a platform created by Valve that distributes games and applications in digital format. This application is a kind of test, in fact it represents the first initiative of IKEA to use virtual reality; the launch has the objective to stimulate the release of feedback from consumers, so as to explore new possibilities of use of virtual reality. The IKEA has, in recent years, been researching new technologies in order to improve the experience of its consumers. This application allows the user to enter a virtual IKEA kitchen in real size. Using the appropriate helmet of the HTC Vive, the consumer is able to explore one of the three possible styles of the kitchen, and to modify and parts, such as the colour of cabinets and drawers. Another feature is the possibility to look at the kitchen from different perspectives, reducing or increasing its size, so the viewer can see the environment from the point of view of a child or a very tall adult, but also move around it as if it were real. This can be particularly useful for the users, as this opportunity allows new design possibilities to be identified that would otherwise be impossible to discover. Martin Enthed, IT director for IKEA Communications, says: "Within IKEA we see this new application as an opportunity to "co-create" with people around the world. We hope that users will contribute to the development of virtual reality by giving us their feedback and ideas on how to use this new technology, and how to improve the application we have already released.

\section{CONCLUSIONS}

Even if VR and, in general, immersive technologies are not something which has been created today, it's just now that they are spreading, thanks to the advancement in technology and in particular the use of these tools within the video gaming industry.

Despite this use being the leading one for VR, many other fields can benefit from its use. In this paper, an overview of these sectors is done, with particular interest to what immersive technologies can represent for enterprises and business strategies, in the fields of communication, marketing, sales, advertising, but also manufacturing, design and even home furnishing and real estate.

We are just witnessing the beginning of a new technology which has the potential of becoming pervasive and more and more used both at the mainstream level and at the enterprise level.

\section{REFERENCES}

[1] Anthes C. et al., "State of the art of virtual reality technology", 2016, ISBN: 978-1-4673-7676-1.

[2] Brandon J., "6 amazing uses for virtual reality in business", 2016, online article.

[3] Brandon J., "Is virtual reality finally ready for business use?", 2015, online article.

[4] Carrier J.C. et al, "Virtualism”, 1998, ISBN: 1859732429

[5] Cave K., "beyond marketing \& gaming: 6 professional uses for Virtual Reality", 2016, online article.

[6] Dabbs A., "Kobayashi Maru gets real: VR and AR in meatspace today", 2016, online article. 
[7] De Angelis T., "Il capitale nell'epoca della realtà virtuale e dell'intelligenza artificiale", 2016, online article.

[8] Enderle R., "Virtual reality is really better for business", 2016, online article.

[9] Gaudin S., "5 ways to use virtual reality in enterprise", 2015, online article.

[10] Grig E., "The business of virtual reality", 2016, online article.

[11] Jacobsohn S., "Virtual reality in the enterprise", 2016, online article.

[12] Korolov M., "Virtual reality gains a small foothold in the enterprise", 2014, online article.

[13] Kunkel N. et al., "Augmented and virtual reality go to work", 2016, online article.

[14] Laskowski N., "Augmented and virtual reality make play for the enterprise", 2016, online article.

[15] Maddox T., "Research: $67 \%$ considering adoption of augmented reality in the enterprise", 2016, online article.

[16] Oliver T., "Experience cruises in VR with Carnival", 2016, online article.

[17] Oliver T., "Fiji Airways is letting you experience Fiji in VR in Singapore", 2016, online article.

[18] Oliver T., "How to effectively use VR Marketing (and where it doesen't work)" 2016, online article.

[19] Parisi T., "Learning Virtual Reality: Developing Immersive Experiences and Applications for Desktop Web and Mobile", O'Reilly Media Inc., 2015.

[20] Russell A., "The enterprise applications of virtual reality", Spring 2015, online article.

[21[ Williams C, "Microsoft to overhaul Windows $10 \mathrm{UI}$ - with a 3D Holographic Shell", 2016, online article.

[22] Zuo M., "Alibaba uses virtual reality to make shopping more interactive", 2016, online article. 